\title{
Designing Iran sport for all model
}

\author{
Mohammad Javadipour ${ }^{1}$, Monireh Ali ${ }^{2}$, Rezvan Hakimzadeh ${ }^{1}$ \\ ${ }^{1}$ Psychology \& Education, Tehran University, Tehran, Iranian \\ ${ }^{2}$ Physical Education Organization (PEO), Tehran, Iranian
}

Email address:

javadipour846@yahoo.com (M. Javadipour),m_everlady@yahoo.com (M. Ali)

\section{To cite this article:}

Mohammad Javadipour, Monireh Ali, Rezvan Hakimzadeh. Designing Iran Sport for all Model. American Journal of Sports Science. Vol. 2, No. 3, 2014, pp. 56-64. doi: 10.11648/j.ajss.20140203.12

\begin{abstract}
The purpose of this research is to describe and diagnose Iran Sport For All status and to design a model. The population of the research includes: Sport For All Federation managers, its strategic Council members, its sub sport Associations and Sport For All provinces Units. TO benefit the experts and authorities' point of view effectively, a questionnaire within the framework of the federation strategic plan content was designed and sent to the target population including: different federations and associations managers, the provinces sports units and the federation strategic Council members. A five -level Likert scale (strongly agree /agree/ neutral/ disagree/ strongly disagree) was designed. After Investigating and analyzing the results; regarding a Pathological view and approach; Sport For All strong \& weak points, treats and opportunities (SWOT) were recognized. Then considering the proportion of Sport For All processes role to the other sports and its relationship with procurement, management and processing control components and culture \& religious values, Iran Sport For All development model was designed noticing sport management scientific structure, processing structure and its relationship with other sports and macro management circles for macro policy-making, planning and procurement \& executive levels.
\end{abstract}

Keywords: Theoretical Framework, Model (Pattern) Designing, Iran Sport for All

\section{Introduction}

As science and technology develops management and planning play effective roles in social and executive organizations. The experts, who introduce development as the only principled and logical way to economical growth and blossoming, science and technology progress, achieving public welfare and improvement of living conditions, have frequently spoken on this subject and encouraged statesmen to run along the development programs framework. Development is a purposeful process which is started by human being and its goal is to improve all the people's living conditions in a society.

Considering development based on any definition, interpretation or view finally leads to a single concept to get to happiness, growth, justice, economic, social and cultural dynamism \& freedom. So we should accept that development isn't a spontaneous phenomenon but a matter which we need to have a goal and a plan and hard attempt to achieve it. In this way, studying the developed countries reveals that achieving the sustainable development isn't possible without any attention to the young, rational, creative, dynamic and open -minded people. And those countries which had remarkable success, has based their development on their people's physical and mental education and training progress. The effect of thinking method on one's performance and the necessity of establishing a regular and coherent system for the individuals' thinking so that they could play the best role in making decisions, problem solving and leading organizations, themselves and others to get a successful result for their country is a vital and necessary matter. Real development and progress in countries have different indexes which one of the most important is sport. According to the well-known slogan: "A healthy mind locates in a healthy body", the argument on sport applications to human resources development in different economic, social and cultural fields, is more noticed.(1) Civilization and increasing progress in modern technology have resulted in "Sedentary behavior". This inactivity and Sedentary behavior causes some disorders which affect different physical, psychological and social aspects of life. Changing the status quo needs suitable and deserving tools like physical activity as a multidimensional tool with vast health, economic, social effects which helps healthy leisure time and creates liveliness and vitality. The undeniable 
educating and training role of physical activities specially among teenagers and young people, its role in prevention of diseases, social corruptions and obliquities are just some of the functions of this valuable phenomenon.(2,3)Those people, who do regular sport exercises, have less risk of heart attack. At the same time their brain relaxes more, their heartbeats decrease while resting and they feel less stress and more self-confidence. They are more optimistic and feel less depressed as well. $(2,4)$ Although there are different approaches toward sport as a phenomenon which some of them focus on competitive perspective and the others focus on public health and the vitality of the society and some of the other ones notice the economic perspective, but regardless of all these matters ,the importance of physical education and sport is increasing day by day. The relationship between sport and other cultural, social, political and economic phenomena reveals its importance and role in the countries national development programs and in a general point of view, sport development and progress in each country has a close relationship with the power and authority of that country.(5) Sport For All or Sport For all groups of people is a main part of sport which has close relationship with the health and the vitality of the society and a lot of sport main approaches are located in it. A lot of developed countries have chosen and accepted the health approach as their sport policy and run on the basis of this approach. These countries haven't mentioned the medal achievement (competing) in international fields or championships and professional approaches in their sport policies.

Among all kinds of sports especially in comparison with competitive (athletic) and professional sports, Sport For All has had a main and basic role which includes a great number of functions. (Mull 2005) Sport For All has been defined as all forms of extensive and comprehensive sport activities among all ages, genders, races, religions and nations with different physical and psychological abilities.(1)According to this definition, Sport For All isn't a duty, but an opportunity. It's not a collective sport but an individual and team one. In fact the people's motivation to participate in sport activities isn't getting to high ranks and achieving the Olympic motto (Faster, Higher and Stronger).Health, vitality and social relations are the main factors in taking part in these activities. Competition and wining \& losing play the least role in their tendency toward sport.(5) Sport For All approaches are as follow: Getting vitality and joy feeling, enrichment of leisure time, getting health and physical fitness, improvement of job relations, connection and social relations and life style, ,prevention and treatment of diseases, achieving the sport results and benefits, happiness and safety, energy balance and detoxifying, controlling and losing the weight and getting to physical fitness, achieving social emotions and improving interaction and social relations.(1)

The researches on the effect of sport activities on physical and psychological health, longevity, vitality, improvement of social relations and enrichment of leisure time have caused an increase in people's participation in different sports specially in their participation in different forms of Sport For All in the world. This is why nowadays most of the world developed countries are competing with each other for their Sport For All organizations and arrangements and are delivering creative programs to improve this sport regularly. It's obvious that each country which cant cross this increased wave will never be able to fill this gap and so its differences with other countries to benefit from the advantages of sport and motor activities will be completely clear.(Dr. Ghare's Plan)Moreover, physical activity improves psychological health and decreases psychological problems.(6,7) Inspecting physical education organization published statistics; we can find that only 10 percent of people participate in sport \& physical activities. This percent is too low in comparison with other countries like Australia where 52 percent do exercise. This Sedentary behavior and insufficient physical activity which comes from development and improvement of facilities, modern comforts and new lifestyles reveal the necessity of planning for physical activities which are needed in the society more.(8) According to UE published data, at least 30 percent of the world teenagers and young people don't have insufficient physical activity. This is a lot more in our country according to the available information. So the sport policy maker's most important duty or responsibility is paying attention to sport development among different people from walks of life. On the other hand sport is considered as a social human right. In 2003, UN has mentioned sport as a social right and expresses that the opportunity to take part in Sport and physical activity is a human right and the governors have to provide this opportunity for all of the people in the society. In some of the countries like Sweden and Finland, the number of sport participants is more than 80 percent of their population. Regarding the history of the world Sport For All and its new approaches and obvious philosophy in a lot of countries and also its focus on multiple approaches like health, vitality of the society, enrichment of leisure time, improvement of job relations, connection and social relations, prevention and treatment of diseases, happiness and energy balance and detoxifying , achieving social emotions and getting to the sport results and benefits, it seems that using all the potentials of the society is necessary to improve and develop Sport For All. Moreover, increasing the awareness of the people in the society can play an important role to form it as a habit. The experience of the well-known countries in this field reveals that Sport For All development and improvement in these countries result from both the government and people's investment and their close cooperation. As the Constitution and Acts of Islamic Republic of Iran demonstrate that making the sport popular among people is the first duty of each sport organization, so it is believed that the result of this research will help the sport authorities to make their strategies out of these results and to be able to do effective measures to improve Sport For All programs. $(2,7,22,23,24)$ Through 
studying the world experience and investigating our country status, this research has designed a model to improve sport and physical education.

This model includes 4 great components (sub-systems) as follow:

*The process of strategies and policies development

* Development of Sport and healthy Recreation

*Supporting Sport development and healthy Recreation and

*Coordination and Supervision

Sport and healthy Recreation are considered as the main process in "Sport and Physical Education Comprehensive System"(Plan). This process has been divided into 4 groups: Sport for All and Recreation, Educational Sport, Competitive (Athletic) and Professional Sport. Sport For All Movement in the world was started in 1960 in Europe by organizing Trim Associations (A Norwegian word means fit and fresh).International Sport For All Committee was established in 1964 and Sport For All Federation was formed in 1992 in our country.(17) In a study among 126 countries in the world, it was revealed that although 92 percent of these countries know physical education as a necessary and obligatory phenomenon for all different groups of the society ,but only in 71 percent of them physical education is in harmony with social needs and in 29 percent, its just a mean to get to other non-sport goals.

In 60 percent of developing countries, sport policies just remain on papers and as a motto. This study also shows that there is a big gap between what has been approved and the activities. (7) Razavi et al.(2009) studied Sport For All participants' social and Economical Status(SES) in Mazandaran province. The result of this study, among 384 Sport For All participants in Mazandaran showed that there is a meaningful relation between the number of Sport For All participants and their economical status. However, it seems that these participants mostly belong to mid-level or low-mid level groups. So it seems necessary to plan to omit the available obstacles for increasing the participation among low-level groups and attracting the high-mid level people's attention toward this field. Because this can result to improvement of all Sport For All participants' sports health levels. (3)

Ghafoori(2007) in his research studied different kinds of favorite Sport For All activities and Recreations in the society and offered a model for future plans. The result of his research revealed that the most obstacles in doing sport among the research samples in order of

Priorities are as follow: "The lack of motivation", "The extensive cost of doing sport ", "The lack of space and facilities" and "Time limitation". The result of studying priorities in sport divisions was also considerable. The research participants believed that in the next sport plans "Sport for All and Recreation" should be more focused. Then sport in the schools and universities; "Educational Sport" was located in a short distance and then it came to "Competitive (Athletic) Sport " and "Professional Sport" which were located next to each other in the third and fourth level but in a long distance from the first and second ones.(7) Ghare(2005) conducted the research of "Iran Sport For All status and its comparison with some of the world selected countries". The result of his research indicated that $5 / 92$ percent of Iran population take part in sport activities under the supervision of Men \& Women Sport for All Province Units which was the least percent among 23 countries in the world. Regarding the date of organizing Iran Sport for All official organization, Iran had the lowest rank among 20 countries in the world too. The percentage of participants in Iran Sport For All activities was more than the number of participants in Africa and less than this number in other continents.(2)

Afarinesh(2005) in his research compared different universities faculties, coaches, athletes and managers' points of view on the ways of improving Sport For All. According to the results of his research, the most important factors to improve Sport For All are as follow: Economic improvement of different people from walks of life, Using multimedia, Noticing the family status (number of children, marriage), Holding the sport competitions and awarding the prizes, Increasing public transportation services, Regarding sport as the first priority and at the top of the leisure time list and attracting the private and non-governmental investments. (10) Gholiniya(2004) in his research studied Iran total Sport For All status and challenges facing participation in the sport and planning for making the sport popular among the people. He chose 70 physical education organization managers and experts and 524 citizens living in 10 different provinces as his research sample. The results indicate the use of multiple approaches like Socio-Cultural and Group-Individual Salutary approaches (for implementation), multiple approaches of Active Interference, Participation \& Supervising, RecreationNaturalistic and Cultural \& Local approaches (for finding priorities among sport disciplines), Spaces Combining Ability approaches ( using sport places)

The approaches of Obligation for binding the rules (legal dimensions), the approaches of Modeling from bottom and making culture from top (performing), approach of Ultra mural Activity (cooperation of centers) and etc. in the frame of Offensive-Development and Diversity Strategy. (11) Atighechi(2004) also in a study on the way of spending leisure time found it about 3 to 5 hours per head. He who was studying 2301 university students (like Saneee) revealed the top students' extreme eagerness toward Sport For All rather than Competitive (Athletic) Sport as their popular pastime.(12) Saneee(1994) studied the university students' attitudes on sport regarding the way of spending their leisure time. He studied 700 Teacher Training university students and investigated their way of spending their leisure time. He found that their leisure time was about 3 to 4 hours and most of them were dissatisfied with their way of spending it. The students who answered his questionnaire emphasized paying attention toward Sport for All rather than Competitive (Athletic) Sport. Shafiee(1994) studied the socio-economical status of Sport For All participants .He studied 900 Sport For All participants and 
concluded that the most percent (\% 31/1) of participants belonged to the middle or higher class of socio-economical category. Considering their living place, most of the participants (\% 28/3) were living at the north of Tehran. (14) Ramezani Khalilabadi (1994) studied Sport for All participants' motivation in his research. He achieved the data through collecting the questionnaires answered by 975 participants in Sport for All Stations. The result included: Their first motivation was achieving vitality and joy feeling. Then there were sport advantages and positive effects and also Sport for All enjoyment and safety. Cheap expenses, no need to special sport equipments and facilities and filling their leisure time were as some of their motivations as well. The participants mentioned that multimedia had $42 / 2$ percent role in their eagerness toward sport. Finally their inability to participate in Competitive (Athletic) Sport is mentioned as one of the peoples' motivation toward Sport for All.(15)

Studying Sport for All status in countries like Australia, Germany, Japan, Malaysia, Finland and Denmark reveals that regular plan to develop and improve Sport for All in these countries has a background of about 50 years. There are different factors to get to this success which the first can be mentioned as: Sport for All growth in the framework of these countries national plans and their governments' effective support of the plans. Furthermore, the clubs and sport public places development and establishing and organizing Sport for All forums can be mentioned too. (1)

The main factors in developing Sport for All in these countries are:

1-The governments' support of sport clubs development

2-Rgular development of Sport for All programs

3-Dvelopment of sport places

4-Dvelopment of Sport for All forums

5-Role of governmental institutes

6-Holding festivals and different social events

7-Marketing

8-Making culture to develop Sport for All

9-The national and state governments' financial support

10-Increase in target groups' activities including: The

Youth, Old, Disabled, Schools, Women, Workers and Employees...

11-Having codified and clear strategy and policies to develop Sport for All

12- The role of private organizations

Strategic Planning is a tool for organizing the present on the basis of the projections of the desired future. That is, a strategic plan is a road map to lead an organization from where it is now to where it would like to be in five or ten years. It is a systematic planning process involving a number of steps that identify the current status of the organization including its mission, vision for the future, operating values, needs (strengths, weaknesses, opportunities and threats), goals, prioritized actions and strategies, action plans, and monitoring plans. Strategic planning has long been used as a tool for transforming and revitalizing corporations, government agencies and nonprofit organizations. Recently, however, skepticism about planning has been on the rise. Political and economic uncertainty is the norm and the space of technological and social change has accelerated. Each strategic planning includes three main components as: Plan development, Plan execution, and Plan review. Many of the functional areas within these components are similar in that all three require a team concept that is based on: ensuring the member's roles are defined, educating team members about the process, and using quality communication when interacting Strategic planning is the cornerstone of every commoninterest community. Without strategic planning, the community will never know where it is going-much less know if it ever got there. An important concept of strategic planning is an understanding that in order for the community to flourish, everyone needs to work to ensure the team's goals are met. $(22,23,24)$

Regarding the high frequency of different subjects on Sport For All and its theories and opinions all around the world which indicate its main components and their type of interaction and its relation to different sports, which theoretically is a guide for planning Sport for All development, mainly the growth and development of Sport For All among developed countries is caused by codified plans and the scientific method of performing them.

In our country in spite of different studies in this field, there aren't many scientific and exact studies on Sport for All methodology and designing models for its development. Planning System in our country has a different structure comparing with other countries. Dividing national Sport for All responsibilities and analyzing the government's missions into governing division, organizations and governmental \& non- governmental centers basically needs a model which can make the relationship between Sport for All components and the extramural components which are focused on other sports and the supporting components of Sport for All System. In this research through identifying and studying Sport for All in Iran, we offer a model for its development. Two subjects are investigated in this survey: 1- Revealing Sport for All weak and strength points \& its treats and opportunities.2- Designing a Sport for All development model.

\section{The Research Methodology}

As the nature of this survey is a kind of management and strategic planning survey, we have used different research methods to design a Sport for All development model. Achieving a study model and finalizing it to make a plan, Investigating the history and the available documents, Studying the previous researches and upper level documents, Comparative Studying and obtaining the authorities and experts' point of view need different approaches including management, descriptive or analyzing .This is an applied research and its necessary data, with paying attention to the available Sport For All indexes, have been collected through preparing and sending 
statistics forms to different provinces Sport Units, SubSport Associations and Physical Education Centers. There are Statistics information and data on human resource status, the number and frequency of Sport Units all over Iran, Sport places which are under the supervision of the state and sport events like(competitions, mass walking events, national meetings,...)in this part of the research.

\subsection{Population}

The population of this research includes: Sport for All Federation managers, its strategic Council members, its sub-sport Associations and Sport for All provinces Units.

\subsection{Sample and Sampling Method}

In this research the number of Samples is the same as population.

\subsection{Data Collecting Tool}

TO benefit the experts and authorities' point of view effectively, a questionnaire within the framework of the federation strategic plan content was designed and sent to the target population including: different sport federations and associations managers, the provinces sports units and the federation strategic Council members. As a five-level Likert scale (strongly agree /agree/ neutral/ disagree/ strongly disagree) was designed to answer the questionnaire, it has been decided to accept an idea if it has been achieved $\% 70$ strongly agree or agree opinions. On the other hand, the idea with $\% 50$ disagree or strongly disagree opinions will be omitted.

\subsection{Data Collecting Method}

The necessary data, with paying attention to the available
Sport for All indexes, have been collected through preparing and sending statistics forms to different provinces Sport Units, Sub-Sport Associations and Physical Education Centers.

\section{Results}

As it has been mentioned the population of this research includes: Sport for All Federation \& Associations managers, the directors of the committees, the directors of different provinces Sport Units and the Federation strategic Council members. In this part we are going to show their formal education status and their experiences in Sport for All field.

Table 1. The research population status regarding their Education.

\begin{tabular}{|c|c|c|c|c|c|}
\hline Sex Education & DIP. & & BA & MA & PhD \\
\hline Female & 3 & 0 & 4 & 1 & 0 \\
\hline Male & 5 & 6 & 24 & 10 & 5 \\
\hline
\end{tabular}

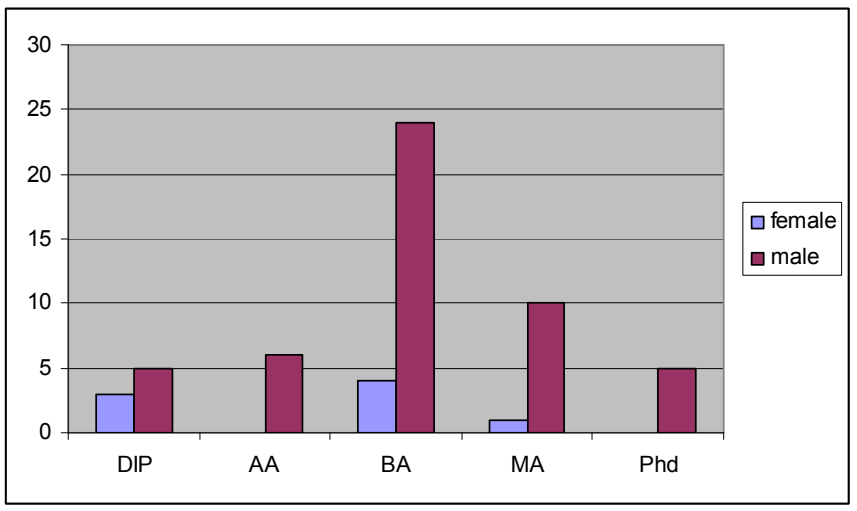

Chart 1. The research population status regarding their Education.

Table 2. The research population status regarding their participation experiences in Sport For All activities.

\begin{tabular}{|c|c|c|c|c|}
\hline sex & Up to 5 years & Up to 10 years & Up to 20 years & 20 year and more \\
\hline female & 3 & 4 & 1 & 0 \\
\hline male & 9 & 17 & 10 & 8 \\
\hline
\end{tabular}

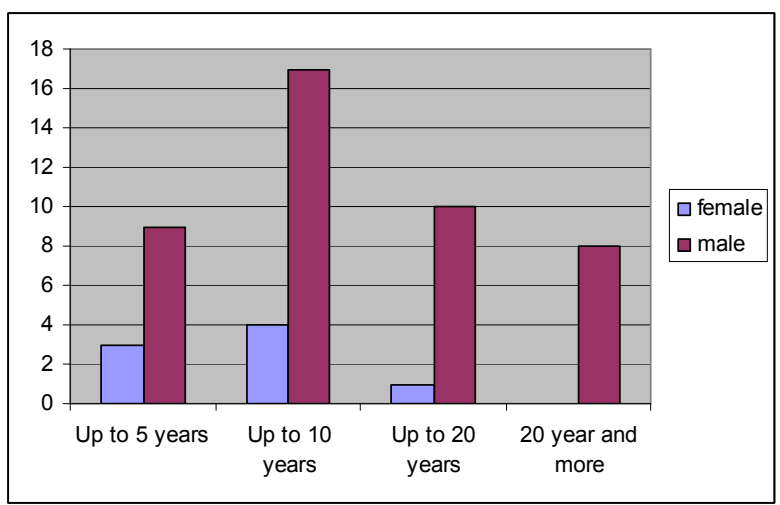

Chart 2. The research population status regarding their participation experiences in Sport for All activities.
According to a pathological approach, after studying and analyzing the results we found the following Sport For All weak and strength points \& its treats and opportunities as follow:

\subsection{Strength Points}

- Individual and organizational motivation and eagerness toward Sport For All and Recreation development and improvement

- Having an independent legal entity and the possibility of using suitable financial and economical mechanisms

- Having the benefit of valuable, experienced human resources (managers, experts, teachers and coaches...)

- Having 32 active provinces Sport Units and 131 active 
towns Sport Units

- Governing more than 22 different sport disciplines which are related to Sport For All and Recreation

- Connecting and being a member of TAFISA(The Association For Sport For All) \& ASFAA(Asian Sport For All Association)

- Close relationship and special notice to National Broadcasting Media and other audio, written ones, ...

- Having the possibility of holding national events like Family Walking, Run Day \& mass walking events on challenge days and so on, Official employees' competitions, Local \& Traditional Festivals, etc.

- Active participation in international Sport For All events

- Having the benefit and cooperation of offices, organizations and governmental or non-governmental and private centers

- Signing memoranda with governmental \& private organizations and centers

\subsection{Weak Points}

- Weakness of information and communication system in Sport For All Federation and adverse use of individual \& organizational information and communication

- Traditional management in Sport For All Federation and its Sport Units

- Insufficient Sport For All governmental budget offering by Physical Education Organization(PEO)and NOC

- The lack of an economic outlook and disability for earning new income sources from the federation activities through marketing and business

- The shortage in Sport For All income and its great dependence to the government and Physical Education Organization public budget

- The lack of a systematic relationship with offices, organizations and governmental and private centers

- The lack of a national comprehensive plan for Sport For All

- $\quad$ The lack of both Sport For All TV channel and a unit management thinking and a central plan

- The lack of Sport For All managers, athletes and authorities' sufficient financial support

- The lack of a common definition of Sport For All and Recreation,which is in harmony with the society needs, among the experts and managers in organizations and centers about sport views and applied concepts

- The lack of a Coherent organization and a structure to provide efficient human resource in the federation related organizations and units

\subsection{Opportunities}

- Focus on Physical Education in Islamic inspiration instructions
- Focus on free Physical Education development and improvement in Iran Constitution

- The Leathers' speeches in the start of the new year (1389: 2010) in Razavi Haram(Mashad)

- The senior authorities, clergymen and medical community's Special notices toward Physical Education development in Iran

- The community attitudes toward sport activities as an effective psychological, physical, cultural, educational and moral factor

- $\quad$ The young population of our country and the great number of sport talents

- Iran four climate variability and natural-sport attractions

- Iran geographical and climatic potentials for Tourism, Ecotourism and Fishing, ...

- Providing the possibility of using the offices, organizations and centers potentials and facilities through signing memoranda

- New and effective views of main organizations toward Sport For All development

- All walks of life people's great participation in weakly Family Walking events within provinces and towns

- Good support of companies and economical institutes to provide the needed financial resources of performing the federation activities

\subsection{Treats}

- The lack of necessary motivation in private divisions for developing facilities and improving national sport activities

- The intrusion of undesirable social and behavioral abnormalities in sport environment

- The lack of a coherent planning system to attract financial and economical nongovernmental resources

- Insufficient recognition of public physical education and Sport For All international potentials

- Inadequate quality and quantity of Asian, World and Olympic standings in Sport For All among the related authorities and experts

- $\quad$ Planning and performing parallel and non-normative activities in national organizations and centers

To design a Sport For All \& Recreation development model in Iran, we have used different sources among them the two most important will be mentioned. It has been noticed that in addition to using the scientific sources to design the final model, with paying attention to social and cultural atmosphere of our society and the administrative and management structure of sport in Iran and the need for Iran Sport For All development model, a realistic and directional model will be used in Sport For All planning system. One of the most important classifications is Mull et al.'s model.(Mull, 2005) He has divided sport into four levels in his book "sport management and Leisure time." 


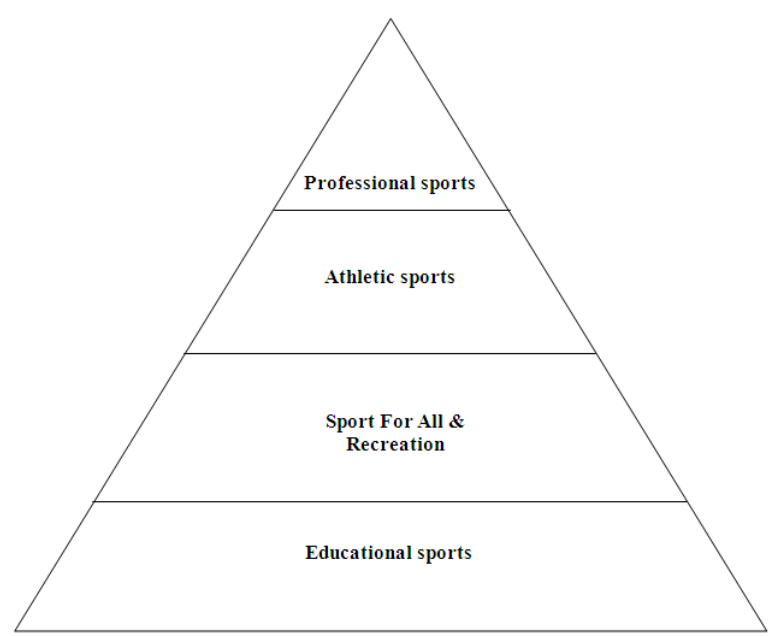

Chart 3. Mull et al. divided sport into four levels (Mull ,2005)

Mull et al. (Mull, 2005) then divided Sport For All \& Recreation concepts into five levels (Chart 4)

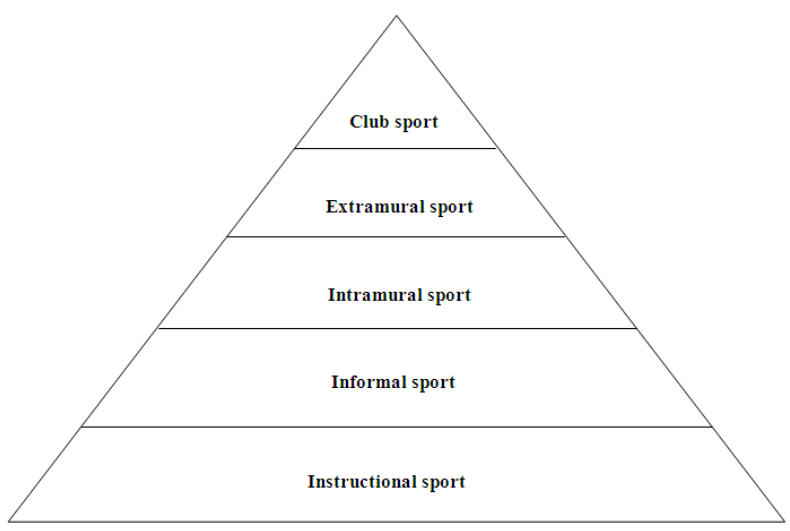

Chart 4. Mull et al. divided sport into five levels (Mull, 2005)

Then Iran Sport For All development model- along with a sports management scientific structure and process structure and its relationship with other sports and high management circles for policy making and designing master (strategic) plans and supportive $\&$ executive levels- was designed with paying attention to the role of Sport For All processes in other sports and its relationship with components like: supporting, management, process control and culture and religious values.

\subsection{Final Suggested Model for Sport For All \& Recreation in Iran}

This model, using the available background in Sport For All scientific sources and for the sake of making the performance of Sport For All_available concepts easier and with paying attention to the management structure attributes and specialties in planning system and Iran socio cultural atmosphere has been designed. To finalize the model the experts and the authorities' opinions have been used. The first level of this study includes Sport For All \& Recreation development and the second level includes the following main processes in chart 5 .
1) Sport for health and motion

2) Sport for treatment and reduction in the effects of chronic diseases

3) Educational sport with approach of training sports disciplines and paving the road to Athletic (Competitive) Sport.

In supporting processes of Sport For All development, some components like human resources, centers, Legal environment, sport places, scientific and research components, management and planning and ICT have been designed.

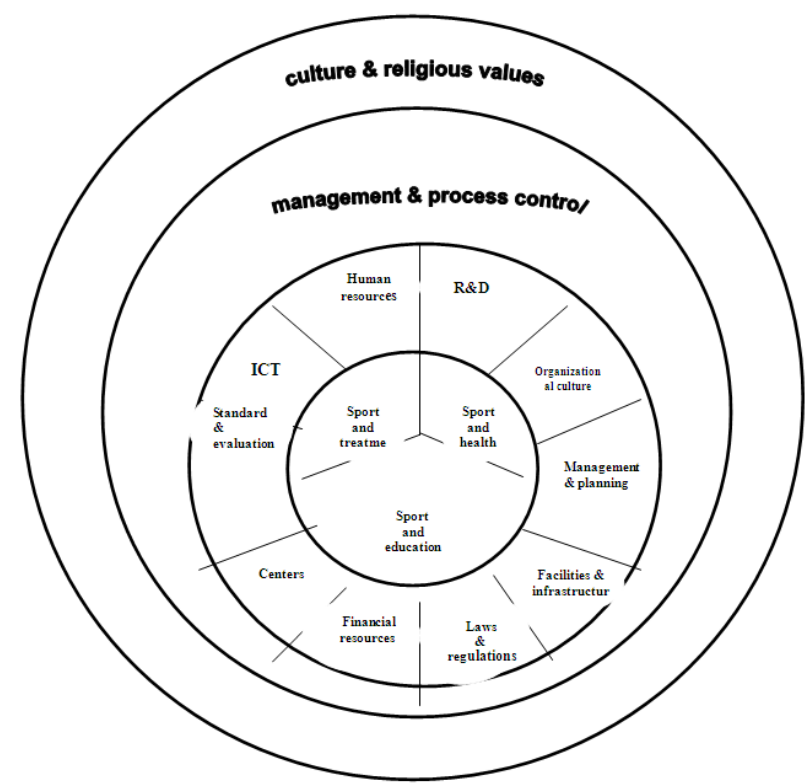

Chart 5. Final suggested model for Sport For All \& Recreation development

\section{Conclusion}

The percentage of participants in Sport For All activities in different countries can show a clear image of the world Sport For All status. Studies show that most of the countries aren't satisfied with their Sport For All and mobility status. In this regard a special notice has been paid to social demands. People's priorities in doing sport activities are very important in these countries and measures are done by paying attention to this point. People's interest to Athletic (Competitive) Sport or Recreation ones can play an important role in performing Sport For All development programs and mobility in these countries. The government budget is one of the important governmental tools in developing this sport. In most of the countries Sport For All budget is more than the others which shows its importance in human societies. The studies reveal that in best situation the number of participants in Sport For All activities isn't more than \%10 in our country.( A Local Strategic Plan For Iran Sport and Physical Education Comprehensive System 2002) Of course in some of the researches you can find it more and even about \%60.(Tondnevis 2002)This is while the percentage of participants in sport activities in some of the countries like Finland and Sweden is more than \%80 . (Bottenburg et al 2005, 
koski 2000, European commission 2004)So it is necessary to perform different micro and macro(master)plans to develop Sport For All in Iran. Paying attention to social demands and people's priorities \& interests is very important too. (Girginov 2001, Echberg \& Midol 1992, Australian sport commission 1999, Gholiniya(2004), Islamic Republic of Iran Broadcasting 1996 ) These priorities, social demands and interests determine which strategies, plans, sports and structures can be effective at the present time and future. Ghafoori(2007) In this research after studying Sport For All in Iran and some other countries(with similar socio cultural attributes and the same level of development)Strength \&Weak points and Opportunities \& Treats(SWOT)are analyzed and Sport For All Federation Strategic Plan was designed which hadn't been noticed separately in other Sport For All researches before. In "Iran Sport and Physical Education Comprehensive Plan" the processes of this sport has been studied completely and its different parts as SWOT analysis, vision, goals and strategies have been used in designing it. The studies in" Iran Sport and Physical Education Comprehensive Plan" are some of the most important and strategic studies among Sport For All ones. Saminiya (2009) studied the pathology and development of Sport For All in Iran based on SWOT model.(2009)A final model to develop Sport For and recreation is designed in this research as well. Ghafoori(2007) in his research titled as:" Different kinds of favorite Sport For All activities and Recreations in the society and offering a model for future plans" designed a model for future Sport For All Federation planning to increase the number of participants in Sport For All activities. Any way no Sport For All model in other researches is designed. In other researches on Sport For All, the status of this sport in people's leisure time and the participants' economic status are focused more. The first level of the designed model in this research emphasizes on Sport For All development and the second level focuses on Sport for health and motion, Sport for treatment and reduction in the effects of chronic diseases, Educational sport with approach of training of sports disciplines and paving the road to Athletic (Competitive) Sport. In a research by Kashef (1996) on Sport For All in West Azerbayjan, Keeping healthy was the participants' main aim and treatment was the less important one. In another research Kashef (2000) studied Iran Sport For All status and suggested some recommendations to develop it. In this research the most participants' motivations were public health, recreation, weight loss and treatment of diseases in turn. Having a review on the performed researches out of the country shows that the people's eagerness toward Sport For All is increasing. Countries like Australia, Germany, Canada, Sweden, Japan, Holland, Switzerland and France are more active in Sport For All. This reveals that personal and social health is more important in developed countries and they have paid attention to people's satisfaction \& participation to have healthy life, Social solidarity and economic development among People of all walks of life in writing their strategic plan. If we are going to profit Sport For All advantages we should invest for it.

\section{Suggestions and Solutions}

- $\quad$ The Institutions affecting Sport For All specially The Ministry of Youth \& Sport and Sport For All Federation should use strategic models to design their strategic plans.

- The main process of Sport For All development on the base of the suggested model and the scientific models has been designed in three parts as health, education and prevention of the diseases. It is necessary to have a written and scientific plan to connect and coordinate them to each other and to Educational and Athletic (Competitive) Sport.

- In spite of great similarities among these concepts, it should be noticed that because of their natural differences in Sport For All, their supporting components should be selected separately.

- $\quad$ The pathology of Sport For All in Iran shows that Sport For All system in Iran, in spite of its opportunities, should overcome its weaknesses.

- According to this pathology, Iran Sport For All strategic position is in growth and development level. To improve this strategy in Sport For All we need a Sport For All Development Model.

- It is necessary to determine some mechanisms which bind the performance of the rules and regulations, plan documentations in upper level documents, task orientation in Sport For All and make the sport popular in the society.

- Involving private and nongovernmental centers in policies while binding both profitable and non profitable approaches.

- Notice and focus on Customer Access Multistage Model with an emphasis on contingency and cultural infrastructures.

- Prediction of both Offensive - Development and Diversity Strategies considering SWOT.

\section{References}

[1] Mohammad .Javadipour, (2011).Sport For All Federation Strategic Plan, Research Design; Ministry of Youth \& Sports, Sport For All Federation.

[2] Mohammad Ali. Ghare, (2004). Iran Sport For All status and its comparison with some of the world selected countries; PhD. Dissertation. Tehran Teacher Training University, Sport and Physical Education Collage.

[3] Mohammad Hosein. Eshkooh, Reza. Razavi, Taheri, (2010).Sport For All participants' social and Economical Status (SES) in Mazandaran province; Move Sport Management Journal, (2010/ summer), $5^{\text {th }}$ Vol., pp 21-34.

[4] Fatemeh. Niknejad, (1996) Asking Tehran women's idea about Women Sport; Deputy of Women Sport and Physical Education in Physical Education Organization.

[5] Sport For All and Recreation Development detailed studies ;( 2002).Iran Physical Education Organization, 1st version. 
[6] Hasan. Asadi, Mohammad Reza. Ahmadi, (2000). Comparing the athletes and non- athletes students' psychological health in Sanandaj town high schools; Movement Issue, pp 36-46.

[7] Farzad. Ghafoori, (2007) .Different kinds of favorite Sport For All activities and Recreations in the society and offering a model for future plans; Research design.

[8] Mir Mohammad. Kashef, (2000). Studying Iran Sport For All status and suggesting some recommendations to develop it; Abstract. Essays of the 4th Physical Education and Sport Sciences National Meeting. pp 86-87.

[9] Maryam. Momtazbakhsh, (2006). Investigating the strategies of developing and improving Sport For All among women working in Military Sciences University; Military Knowledge Journal, 9th year.2nd no, pp53-62.

[10] Akbar. Afarinesh Khaki, Fereydoon. Tondnevis, Seyed Amir Ahmad. Mozafari, (2005). Comparing different universities faculties, coaches, athletes and managers' points of view on the ways of improving Sport For All ; Sport and Movement Sciences Issue, (2005/ summer); 3(5):22-1.

[11] Mohammad Javad. Gholiniya, (2004).Paving the road and Planning for making the sport popular among the people; Research design, Physical Education Organization.

[12] Atighechi,Akram,(1995). Investigating the ways of spending Zanjan city female university students' leisure time focusing on physical education role. MA Thesis. Tehran Central Branch Islamic Azad University.

[13] Saeed. Saneee, (1995). Investigating the ways of spending Tehran Teacher Training University students' leisure time focusing on physical education role; MA Thesis, Tehran Teacher Training University.

[14] Mohsen. Shafiee, (1994). Investigating the socioeconomical status of Sport For All participants in Tehran city. MA Thesis. Tehran Teacher Training University.

[15] Gholam Reza. Ramezani Khalilabadi, (1994). Investigating the Sport For All participants' motivation in Tehran city; MA Thesis, Tehran Teacher Training University.

[16] Mona. Saminiya, (2011). The pathology and development of Sport For All in Iran based on SWOT model; MA Thesis, Mashhad Central Branch Islamic Azad University.

[17] Bottenburg, van M.; Rijnen, B. and van Sterkenburg, J. (2005). Sports participation in the European Union; Trends and differences. Arko Sports Media, Nieuwegein, Netherlands.

[18] European Commission (2004b) The citizens of the European Union and sport. Special Eurobarometer 62.0 213.TNS Opinion and Social c/o EOS Gallup Europe.

[19] Koski, P. \& Heikkala, 1. (1998) Suomalaisten urheiluorganisaatioiden muutos. [National sports organisations in the process of professionalisation]. Jyvaskylan yliopisto, liikunnan sosiaalitieteiden laitos, tutkimuksia no.63. Jyvaskyla.

[20] United Nations (2003) "Sport for Development and Peace: Towards Achieving the Millennium Development Goals"; Report to Inter-Agency Task Force on Sport for Development and Peace; Available on: www.undp.bg.

[21] Council of Europe (2005). "Sport for all". Available on: www.coe.int

[22] Strategic planning. Report \#3. Published by the foundation for community association research.

[23] Strategic planning handbook.(2001).Compiled by special libraries association.

[24] Richard A.Mittenthal. (2002). Ten keys to successful straregic planning for nonprofit and foundation leaders. 